\title{
Comparison of the immediate effects of gaseous ozone and chlorhexidine gel on bacteria in cavitated carious lesions in children in vivo
}

\author{
Irmgard Hauser-Gerspach • \\ Victoria Pfäffli-Savtchenko • Jan Eric Dähnhardt • \\ Jürg Meyer • Adrian Lussi
}

Received: 18 July 2008 /Revised: 22 October 2008 / Accepted: 31 October 2008 / Published online: 26 November 2008

(C) Springer-Verlag 2008

\begin{abstract}
Clinical application of ozone gas has been shown to arrest the progression of dentinal caries in children. In this study, we compare the immediate effects of gaseous ozone and chlorhexidine gel on bacteria in cavitated carious lesions in children. Forty children, each with at least two open occlusal carious lesions, were enrolled in the study. Two teeth were chosen randomly. In one lesion, overlying soft biological material was removed, whilst the other lesion was not excavated. Cavities were rinsed with sterile water and dried with air. A standardised sample was taken from the mesial part of each lesion. Then, gaseous ozone (HealOzone) or $1 \%$ chlorhexidine gel (Corsodyl) was applied for $30 \mathrm{~s}$ on both lesions of 20 children each, and a second sample was taken from the distal part of each lesion. The anaerobic microbiota was cultivated; the number of colony forming units was calculated per milligram sample. The twosided paired $t$ test showed no significant $(P>0.05)$ differences in the reduction of total bacterial counts per milligram
\end{abstract}

Irmgard Hauser-Gerspach and Victoria Pfäffli-Savtchenko contributed equally.

I. Hauser-Gerspach · J. Meyer

Institute of Preventive Dentistry and Oral Microbiology,

School of Dental Medicine, University of Basel,

Basel, Switzerland

V. Pfäffli-Savtchenko · J. E. Dähnhardt · A. Lussi

Department of Preventive, Restorative and Pediatric Dentistry,

School of Dental Medicine, University of Bern,

Bern, Switzerland

A. Lussi $(\square)$

Klinik für Zahnerhaltung, Präventiv-und Kinderzahnmedizin,

Universität Bern,

Freiburgstrasse 7,

CH-3010 Bern, Switzerland

e-mail: adrian.lussi@zmk.unibe.ch comparing samples before and after ozone or chlorhexidine application. The tests also showed no statistically significant difference whether the superficial decayed dentine had been removed before ozone or with chlorhexidine treatment or not. It can be concluded that gaseous ozone or chlorhexidine gel application for $30 \mathrm{~s}$ to deep occlusal carious cavities had no significant immediate antimicrobial effects whether the superficial decayed layers dentine were removed or not.

Keywords Ozone · Chlorhexidine · Caries · Children . In vivo

\section{Introduction}

Dental caries is a microbially mediated disease characterised by demineralisation of the tooth. Untreated, it leads to cavitation, discomfort, pain and eventual tooth loss. It is one of the most common diseases affecting the world's population and often resulting in reduced quality of life [32, 35]. Tooth loss in children, especially the primary second molars, may lead to reduction of the arch length causing crowding [12]. Furthermore, there is a direct relationship between caries experience in the primary and the permanent dentition [17]. In Western societies, the prevalence of dental caries has shown a remarkable decline in children and adolescents during the last four decades. Occlusal pit and fissure caries accounts for the majority of lesions in the age group of 8- to 15 -year-olds $[4,21]$. Furthermore, a small proportion of children aged 6 years and under experience profound carious destruction of deciduous molars [11, 20, 28].

Restorative therapy in primary teeth is essential but is not always easy. Many children are anxious to attend the dentist; $35 \%$ of the 5 -year-old and $21 \%$ of the 12 -year-old 
children are afraid to go to the dentist [9]. Stepwise caries excavation with incomplete dentine caries removal may be the treatment of choice in some cases [25, 26]. Unfortunately, in some children, carious lesions have progressed to an extent that treatment under general anaesthesia is required. Certainly, the young patients and their parents would welcome treatment modalities without drilling.

The bacterial flora associated with carious lesions is very complex and highly diverse between different lesions [6, 19]. To arrest caries progression, several antimicrobial agents have been studied in vitro and clinically. The application of ozone has recently been proposed for the treatment of caries. Ozoned water and ozone gas reduced the total cultivable microbiota significantly in vitro $[2,3]$. The clinical use of ozone gas (HealOzone unit, KaVo, Germany) has been shown to arrest the progression of dentinal caries in children after the removal of the gross part of the decayed dentine [10]. The hardness values improved significantly in the ozone-treated group after 4, 6 and 8 months compared with baseline, whilst the untreated control group showed no significant improvement. Previous reports on ozone treatment were critically evaluated $[1,7,30]$. No published data on the penetration depth of ozone gas into dentinal caries lesions are available.

Of all available antimicrobials in dentistry, chlorhexidine is still the most frequently used agent to reduce plaque aiming at caries control [33]. Chlorhexidine in various formulations has a strong antibacterial effect on oral bacteria, notably Streptococcus mutans. It is very effective in vitro against planktonic bacteria, but less effective on bacteria embedded in oral biofilms [29].

To our knowledge, the antimicrobial effects of both ozone and chlorhexidine have not been studied in small children. The primary objective of this study was to evaluate the effectiveness of gaseous ozone as a disinfectant in reduction of microorganisms in occlusal caries lesions of small children with and without excavation and to compare it to the effectiveness of a chlorhexidine gel.

\section{Materials and methods}

\section{Clinical procedures}

All children were patients referred to the Department of Preventive, Restorative and Pediatric Dentistry of the Dental School, University of Bern because several attempts made to treat them in private praxis had been unsuccessful. Therefore, they received dental treatment under general anaesthesia in the Children's Hospital of the University of Bern. All parents of the young patients gave informed written consent for both dental treatment under general anaesthesia and for participating voluntarily in the study, which has been approved by the local independent Ethics Commission of the Canton of Bern (CEC application no. 38/05).

A total number of 40 patients with at least two open occlusal carious lesions (OOCLs) in primary molars, accessible to a dental excavator (EXD 3CH, HuFriedy KKUNITY USA), were enrolled in the study. The ozone application device was a novel ozone delivery system (HealOzone, $\mathrm{KaVo}$ ). It is a portable ozone delivery system with an ozone generator which delivers ozone at a concentration of $2,100 \pm 200 \mathrm{ppm}\left(615 \mathrm{ml} / \mathrm{min}\right.$ of $\mathrm{O}_{2}-\mathrm{O}_{3}$ at a low concentration of $4 \mu \mathrm{g} / \mathrm{ml}$ ). This device delivers ozone through a hand piece directly to the carious lesion with a changeover of 300 times per second. A silicon cup determines the area covered. The cups are constructed in a manner that they are able to tightly seal the area. According to the manufacturer, there are no ozone leaks from the system into the mouth. If there was a leak in the system, the ozone delivery system would automatically stop. Chlorhexidine was applied as Corsodyl ${ }^{\circledR}$ gel (GSK, Weybridge, GB) containing $1 \%$ chlorhexidine (CHX).

Examination of the children was performed under general anaesthesia. Two carious teeth were chosen randomly. In one lesion, the overlying soft biological material was removed; the other lesion was left untouched. Both lesions were examined using a visual/tactile method. Each OOCL was classified in terms of colour, cavitation, size and hardness. The colour was described as yellow, light brown and dark brown [18]. Cavitation was measured on bite-wing X-rays that are routinely taken when children are treated under general anaesthesia. The cavitation depth was measured in millimetres from the mesial cusp to the cavity floor. The size was determined by measuring the occlusal surface and put in three categories: up to one third of the area cavitated, one third to two thirds cavitated and area greater than two thirds cavitated. The hardness was categorised as hard, leathery or soft [10].

Decayed dentine was removed using a new sterile dental excavator (EXD 3CH, HuFriedy KKUNITY USA). The tooth surface was cleaned with $10 \mathrm{ml}$ sterile distilled water and dried for $4 \mathrm{~s}$ using a dental three-in-one air syringe. Teeth without excavation were cleaned with $10 \mathrm{ml}$ sterile distilled water and also dried using a dental three-in-one air syringe for $4 \mathrm{~s}$. The first samples of lesions were taken from the mesial part of the lesions using standardised customary pressure on the cavity using a sterile dental excavator (EXD $3 \mathrm{CH}$, HuFriedy KKUNITY USA) traversing the lesion from the buccal to the oral cavity limits. Both lesions were wholly exposed to the ozone gas for a period of $30 \mathrm{~s}$. Then, in both lesions, another sample of carious dentine was taken - this time of the distal part of the lesion - in the same way. Once the samples were taken, the conservative treatment by excavating and filling the teeth with composite 
was continued (Fig 1). The ozone application has no effect of the bonding strength of the enamel and dentine [8].

The teeth allocated to the chlorhexidine application were recorded using the same clinical indices, and the lesions were treated in the same manner. Corsodyl ${ }^{\circledR}$ gel was placed with a biangle Swiss-made stainless spatula HCB 2034 into the cavity and left for $30 \mathrm{~s}$. Afterwards, the lesion was washed with $10 \mathrm{ml}$ destilled water using a syringe and dried for $4 \mathrm{~s}$ with air. Sample was taken as in the ozone treatment group. No action stopper was added to the samples.

\section{Microbiological analysis}

Samples were immediately put into pre-weighed sterile vials with Thioglycolate Vision Broth (Biomérieux, Meyrin, Switzerland) and weighed. Then, the vials were immediately stored on ice and transferred for processing within two and a half hours to the laboratory of Oral Microbiology at the Dental School, University of Basel. For microbial analysis, the samples were dispersed by vortexing for $60 \mathrm{~s}$ to facilitate the extraction of microorganisms from carious dentine and to disperse aggregates. One hundred microlitres of tenfold dilutions were plated onto Columbia agar (Becton Dickinson, San Diego, USA) supplemented with 5\% human blood (Blutspendezentrum Basel, Switzerland), $5 \mathrm{mg}$ hemin (Fluka, Buchs, Switzerland) and $0.5 \mathrm{mg}$ menadione (VWR International, Dietikon, Switzerland) per $1,000 \mathrm{ml}$. The agar plates were incubated in an anaerobic

Selection of teeth

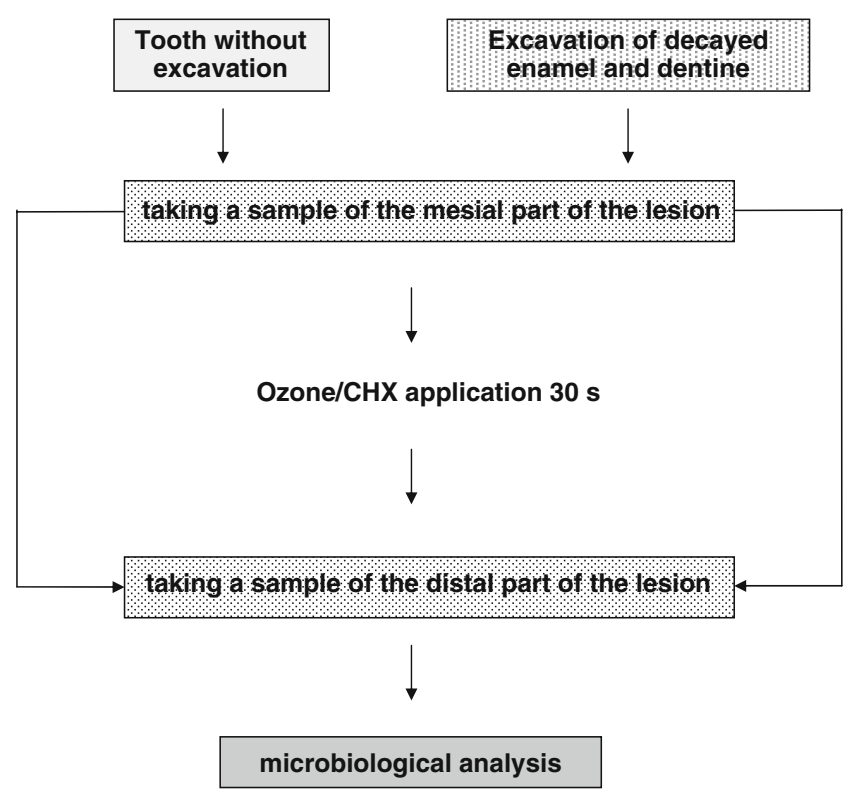

conventional treatment of the child in general anaesthesia

Fig. 1 Flow chart of procedure of the clinical trial chamber with $80 \% \mathrm{~N}_{2}, 10 \% \mathrm{H}_{2}, 10 \% \mathrm{CO}_{2}$ (Scholzen, Luzern, Switzerland) and incubated at $37^{\circ} \mathrm{C}$ for 6 days. Colonies from appropriated dilutions were counted and $\mathrm{CFU}$ were calculated per milligram of sample taken.

\section{Statistical analyses}

Microbiological counts from test and control groups were transformed as $\log$ (colony forming units +1 ) prior to statistical analyses in order to normalise their distributions. Statistical analysis of the data was obtained by paired Student's $t$ tests (Proc Univariate, SAS Institute, Cary, NC, USA) to determine significant differences between groups with and without excavation, with the threshold of significance chosen at 0.05 .

\section{Results}

\section{Clinical variables}

Twenty children (40 lesions) enrolled in the ozone study included of 13 males and seven females. The average age $( \pm \mathrm{SD})$ of the children was $5.1 \pm 1.3$ years (range from 2 years and 8 months to 8 years 7 months), and the average of decayed, missing and filled teeth (dmft) was 12.7. In the chlorhexidine treatment group, also 20 children (40 lesions) were enrolled, ten males and ten females (Table 1). The average age $( \pm \mathrm{SD})$ of the children was $5.1 \pm 1.8$ years at the time of the study (range from 2 years 10 months to 7 years), and the average $\mathrm{dmft}$ was 12.8 . There were no adverse events observed during and after both treatments.

The dominating colors of the teeth were light brown and dark brown. The depth of the cavities was on average $4.5 \pm$ $1.1 \mathrm{~mm}$ for the ozone and $3.7 \pm 1.3 \mathrm{~mm}$ for the chlorhexidine group. Thirty per cent of the cavities were soft, $12.5 \%$ for ozone and $15 \%$ for $\mathrm{CHX}$ were hard, and $57.5 \%$ for ozone and $55 \%$ for $\mathrm{CHX}$ were leathery.

Table 1 Description of the clinical variables

\begin{tabular}{lll}
\hline & Ozone $(n=20)$ & CHX $(n=20)$ \\
\hline Age (mean \pm SD) & $\begin{array}{l}5.1 \pm 1.3 \text { years } \\
13 \text { males/7 females }\end{array}$ & $\begin{array}{l}5.1 \pm 1.8 \text { years } \\
10 \text { males } / 10 \\
\text { females }\end{array}$ \\
& & $\begin{array}{l}12.8 \\
\text { dmft (mean) }\end{array}$ \\
Color of lesion $(n)$ & Y:(9); LB:(17); DB: & Y:(11); LB:(13); \\
& $(14)$ & DB:(16) \\
Lesion depth (mm) & $4.5 \pm 1.1$ & $3.7 \pm 1.3$ \\
Extension of lesion & $<1 / 3:(8) ; 1 / 3-2 / 3:(20) ;$ & $<1 / 3:(10) ; 1 / 3-2 / 3:$ \\
$(n)$ & $>2 / 3:(12)$ & $(18) ;>2 / 3:(12)$ \\
\hline
\end{tabular}

$Y$ yellow, $L B$ light brown, $D B$ dark brown 
Table 2 Bacterial counts [mean $\pm \mathrm{SE} \log 10(\mathrm{CFU}+1) \mathrm{mg}^{-1}$ ] before and after ozone or $\mathrm{CHX}$ application for $30 \mathrm{~s}$ on carious lesions without or with prior excavation of the overlying soft material

\begin{tabular}{lcc}
\hline Groups & Tooth without excavation $\log 10(\mathrm{CFU}+1) \mathrm{mg}^{-1}$ & ${\text { Excavation of decayed enamel and dentine log10(CFU+1) } \mathrm{mg}^{-1}}$ \\
\hline Before ozone application & $7.93 \pm 0.40$ & $7.50 \pm 0.38$ \\
After ozone application & $7.90 \pm 0.46$ & $7.42 \pm 0.39$ \\
Before CHX application & $8.02 \pm 0.39$ & $7.82 \pm 0.41$ \\
After CHX application & $7.85 \pm 0.48$ & $7.60 \pm 0.36$ \\
\hline
\end{tabular}

No statistical significant differences before and after ozone applications and before and after CHX applications

Effect on cultivatable microflora

The total cultivatable anaerobe microbiota was in the order of $10^{7} / \mathrm{mg}$ sample. The total reduction in the group without excavation was $7 \%$ after ozone treatment and $36 \%$ after chlorhexidine treatment in the group with excavation $19 \%$ (ozone) and $41 \%$ (chlorhexidine). There was no significant difference $(P>0.05)$ comparing samples before and after ozone or chlorhexidine treatment and comparing samples from excavated and non-excavated lesions (Table 2).

\section{Discussion}

Clinical application of gaseous ozone appears attractive for the treatment of cavitated occlusal and root caries lesions in cases where restorative treatment is not possible, e.g. anxious children. In theory, ozone can reduce the bacterial load in active carious lesions and thus may at least temporarily stop caries progression. Evidence from in vitro studies using gaseous ozone remains controversial: Some authors found significant inactivation of $S$. mutans in a tooth cavity model [27], whilst others recorded an unsatisfactory efficacy on bacteria organised in experimental biofilms [22, 34]. Ozone treatment of non-cavitated occlusal caries lesions did not result in a significant reduction of the numbers of viable bacteria in infected dentine underneath [5]. In the present study, the gaseous ozone applied to cavitated occlusal lesions in vivo failed to significantly reduce the number of bacteria in the lesion as did CHX. This is in line with the similar study cited [5], but is at variance with very large reductions in root caries lesions reported previously [2, 3]. Possible reasons for the discrepancies could be the different sampling techniques or the size of lesions analysed in this study (the antimicrobial effects were much smaller in large than in the smallest lesions in the study by Baysan and Lynch [3]).

Failure of the ozone gas to access the bacteria in the tissue (decayed or intact) could be due to strong interactions of the gas with organic material in the superficial layers so that the diffusion within the tissue was greatly hampered. Some significant reductions in viable bacterial counts were found in vitro after application of ozonated water rather than gaseous ozone [2, 23, 24].

Chlorhexidine has considerable antimicrobial effects against caries-associated bacteria and is considered the gold standard as antiplaque and antigingivitis agent, whilst its use as anticaries agent is disputed [33]. Most clinical studies evaluating the effect of CHX gel measured the salivary levels of mutans streptococci and found moderate to significant reductions in samples taken $24 \mathrm{~h}$ after gel application [16, 29]. However, mutans streptococci were less sensitive to CHX when located in an experimental biofilm and even less so in mixed biofilms $[14,15,36]$. The reduced sensitivity was explained by bacterial interactions and binding of CHX to proteins and the extracellular matrix in the biofilm $[15,36]$. As a result, the agents may not reach the deeper layers of the plaque, as was shown for chlorhexidine treatments $[15,36]$. If the same mechanism operates in cavitated carious lesions, with many different bacterial species, this could explain the observed lack of efficacy of chlorhexidine. Furthermore, several tooth components such as dentine, hydroxyapatite or collagen, being present under in vivo condition, have been shown to be able to weaken or inactivate the antimicrobial effect of CHX [13]. Nevertheless, repeated applications of $0.2 \%$ CHX can effectively reduce biofilm formation in vitro [31]. Another factor contributing to the small effect of CHX could be its substantivity, potentially leading to an extended action during transport of the samples.

In conclusion, ozone application as well as $1 \%$ chlorhexidine gel application for $30 \mathrm{~s}$ was not effective in reducing microorganisms in open occlusal carious lesions. The removal of decayed tissue had no effect either. Based on this findings, further studies should investigate if repeated or longer applications have significant effects.

Conflict of interest The authors declare that they have no conflict of interest.

\section{References}

1. Azarpazhooh A, Limeback H (2008) The application of ozone in dentistry: a systematic review of literature. J Dent 36:104-116 
2. Baysan A, Whiley RA, Lynch E (2000) Antimicrobial effect of a novel ozone-generating device on micro-organisms associated with primary root carious lesions in vitro. Caries Res 34:498-501

3. Baysan A, Lynche E (2004) Effect of ozone on the oral microbiota and clinical severity of primary root caries. Am J Dent 17:56-60

4. Baysan A, Lynch E (2006) The use of ozone in dentistry and medicine. Prim Dent Care 13:37-41

5. Baysan A, Beighton D (2007) Assessment of the ozone-mediated killing of bacteria in infected dentine associated with noncavitated occlusal carious lesions. Caries Res 41:337-341

6. Becker MR, Paster BJ, Leys EJ, Moeschberger ML, Kenyon SG, Galvin JL, Boches SK, Dewhirst FE, Griffen AL (2002) Molecular analysis of bacterial species associated with childhood caries. J Clin Microbiol 40:1001-1009

7. Brazzelli M, McKenzie L, Fielding S, Fraser C, Clarkson J, Kilonzo M, Waugh N (2006) Systematic review of the effectiveness and cost-effectiveness of HealOzone for the treatment of occlusal pit/fissure caries and root caries. Health Technol Assess 10:iii-iv; ix-80

8. Celiberti P, Pazera P, Lussi A (2006) The impact of ozone treatment on enamel physical properties. Am J Dent 19:67-72

9. Chadwick BL, Hosey MT (2007) Child taming. How to manage children in dental practice. Quintessence, London

10. Dähnhardt JE, Jaeggi T, Lussi A (2006) Treating open carious lesions in anxious children with ozone. A prospective controlled clinical study. Am J Dent 19:267-270

11. Gizan S, Vinckier F, Declerk D (1999) Caries pattern and oral health habits in 2-6-year-old children exhibiting differing levels of caries. Clin Oral Invest 3:35-40

12. Graber TM, Vanarsdall RL, Vig KWL (2005) Orthodontics: current principles \& techniques, , th edn, 4th edn. Mosby, St. Loius, MO

13. Haapasalo M, Qian W, Portenier I, Waltimo T (2007) Effects of dentin on the antimicrobial properties of endodontic medicaments. J Endod 33:917-925

14. Kara D, Luppens SB, ten Cate JM (2006) Differences between single- and dual-species biofilms of Streptococcus mutans and Veillonella parvula in growth, acidogenicity and susceptibility to chlorhexidine. Eur J Oral Sci 114:58-63

15. Kara D, Luppens SB, van Marle J, Ozok R, ten Cate JM (2007) Microstructural differences between single-species and dualspecies biofilms of Streptococcus mutans and Veillonella parvula, before and after exposure to chlorhexidine. FEMS Microbiol Lett 271:90-97

16. Keltjens HM, Creugers TJ, Schaeken MJ, van der Hoeven JS (1992) Effects of chlorhexidine-containing gel and varnish on abutment teeth in patients with overdentures. J Dent Res 9:15821586

17. Leroy R, Bogaerts K, Lesaffere E, Declerck D (2005) Effect of caries experience in primary molars on cavity formation in the adjacent permanent first molar. Caries Res 39:342-349

18. Lynch E, Beighton D (1994) A comparison of primary root caries lesions classified according to colour. Caries Res 28:233239

19. Marchant S, Brailsford SR, Twomey AC, Roberts GJ, Beighton DE (2001) The predominant micro flora of nursing caries lesions. Caries Res 35:397-406
20. Menghini G, Steiner M, Leisebach T, Weber R (2003) Kariesprävalenz von 5-Jährigen in der Stadt Winterthur im Jahre 2001. Schweiz Monatsschr Zahnmed 113:519-523

21. Misra S, Tahmassebi J, Brosnan M (2007) Early childhood caries-a review. Dent Update 34:556-558 561-552, 564

22. Müller P, Guggenheim B, Schmidlin PR (2007) Efficacy of gasiform ozone and photodynamic therapy on a multispecies oral biofilm in vitro. Eur J Oral Sci 115:77-80

23. Nagayoshi M, Fukuizumi T, Kitamura C, Yano J, Terashita M, Nishihara T (2004a) Efficacy of ozone on survival and permeability of oral microorganisms. Oral Microbiol Immunol 19:240 246

24. Nagayoshi M, Kitamura C, Fukuizumi T, Nishihara T, Terashita M (2004b) Antimicrobial effect of ozonated water on bacteria invading dentinal tubules. J Endod 30:778-781

25. Oliveira EF, Carminatti G, Fontanella V, Maltz M (2006) The monitoring of deep caries lesions after incomplete dentine caries removal: results after 14-18 months. Clin Oral Investig 10:134 139

26. Orhan AI, Oz FT, Ozcelik B, Orhan K (2008) A clinical and microbiological comparative study of deep carious lesion treatment in deciduous and young permanent molars. Clin Oral Investig 12:369-378

27. Polydorou O, Pelz K, Hahn P (2006) Antibacterial effect of an ozone device and its comparison with two dentin-binding systems. Eur J Oral Sci 114:349-353

28. Psoter WJ, Zhang H, Pendrys DG, Morse DE, Mayne ST (2003) Classification of dental caries patterns in the primary dentition: a multidimensional scaling analysis. Community Dent Oral Epidemiol 31:231-238

29. Ribeiro LG, Hashizume LN, Maltz M (2007) The effect of different formulations of chlorhexidine in reducing levels of mutans streptococci in the oral cavity: a systematic review of the literature. J Dent 35:359-370

30. Rickard GD, Richardson R, Johnson T, McColl D, Hooper L (2004) Ozone therapy for the treatment of dental caries (review). The Cochrane library, issue 3. Wiley, Chichester, UK

31. Shapiro S, Giertsen E, Guggenheim B (2002) An in vitro oral biofilm model for comparing the efficacy of antimicrobial mouthrinses. Caries Res 36:93-100

32. Steele JG, Sanders AE, Slade GD, Allen PF, Lathi S, Nuttall N, Spencer AJ (2004) How do age and tooth loss affect oral health impacts and quality of life? A study comparing two national samples. Community Dent Oral Epidemiol 32:107-114

33. Twetman S (2004) Antimicrobials in future caries control? A review with special reference to chlorhexidine treatment. Caries Res 38:223-229

34. Walker JT, Bradshaw DJ, Fulford MR, Marsh PD (2003) Microbiological evaluation of a range of disinfectant products to control mixed-species biofilm contamination in a laboratory model of a dental unit water system. Appl Environ Microbiol 69:3327-3332

35. WHO technical report series; 916 (2003) Diet, nutrition and prevention of chronic diseases. World Health Organisation, Geneva

36. Zaura-Arite E, van Marle J, ten Cate JM (2001) Confocal microscopy study of undisturbed and chlorhexidine-treated dental biofilm. J Dent Res 80:1436-1440 